\section{BEACON LIGHTS AND FOG SIGNALS. ${ }^{1}$} I.

I $\mathrm{T}$ is stated by Samuel Smiles in his "Lives of Engineers" that, "with Winstanley's structure on the Eddystone in
6 , may be said to have commenced the modern engineering efforts in directing the great sources of power in Nature for the use and convenience of man," efforts which, followed up by Rudyerd, Smeaton, and others, have been so successful in converting hidden dangers into sources of safety, and insuring the beneficent guidance of the mariner in his trackless path.

The famous structure of Smeaton, which had withstood the storms of more than half a century with incalculable advantage to mankind, became in course of time a matter of anxiety and watchful care to the Corporation of Trinity House, owing to the great tremor of the building with each wave stroke, during heavy westerly storms. The joints of the masonry frequently yielded to the heavy strains, and the sea-water was driven through them to the interior of the building. The upper part of the structure was strengthened with internal ironwork in 1839 , and again in 1865. On the last occasion it was found that the chief mischief was caused by the upward stroke of the heavy seas against the projecting cornice of the lantern gallery, thus lifting this portion of the masonry, together with the lantern above it. Unfortunately, the portion of the gneiss rock on which the lighthouse was founded had become seriously shaken by the heavy sea strokes on the tower, and the rock had thus been seriously undermined at its base. The waves rose during storms considerably above the summit of the lantern, thus frequently eclipsing the light, and altering its distinctive character from a fixed light to an occulting. This matter of distinctive character in a beacon light was one of little importance at the date of the erection of Smeaton's lighthouse, when coal fires were the only illuminating agents along the coasts; but with the rapid development of our commerce, and the great increase in the number of coast lights, it has become an absolute necessity that each light maintain a clearly distinctive character. It was therefore determined by the Trinity House, in 1877 , to erect a new lighthouse at a distance of $\mathbf{2} 20$ feet from Smeaton's tower, where a safe and permanent foundation was found, but at a much lower level, which necessitated the laying of a large portion of the foundation masonry below low water. The foundation-stone of this work was laid on August 19, I879, by H.R.H. the Duke of Edinburgh, Master of the Trinity House ; assisted by H.R.H. the Prince of Wales, an honorary EIder Brother of the Corporation.

On June I, I88I, H.R.H. the Master, when passing up the Channel in H.M.S. Lively, landed at the rock and laid the last stone of the tower; and on May is of the following year H.R.H. lighted the lamps, and formally opened the lisht. house. The edifice was thus completed within four years from its commencement, at a cost of $£ 59,255$. The work was executed under the immediate direcion of the Trinity House and their Engineer, and with a saving of $f 24,000$ on the lowest sum at which it had been found that it could be executed by contract. Every block of granite in the structure is dovetailed together both vertically and horizontally, on a system devised by my father, and first adopted at the Hanois Rock Lighthouse off the west coast of Guernsey. The illuminating apparatus consists of two superposed oil lamps, each of six concentric wicks, and of two drums of lenses of 920 millimetres focal distance, twelve lenses in each drum. The optical apparatus is specially designed on the system of Dr. John Hopkinson, F.R.S., for a double flashing light, and shows two flashes in quick succession, at intervals of half a minute. Attention has of late been directed to the subject of superposed lights in lighthouses, which became a necessity when several small luminaries had to be substituted for the large coal or wood fire of our early lighthouses. The credit of first superposing lighthouse luminaries is doubtless due to Smeaton, who lighted his lantern, in 1759 , with twenty-four large tallow candles in two tiers. The idea was followed in 1790 with the first revolving light, established at the St. Agnes Lighthouse, Scilly Islands, which consisted of fifteen oil lamps and reflectors, arranged in three gruups, and in three tiers. The number of the lamps and reflectors at this and other first class lights was afterwards extended to thirty, and in four tiers. In I859, Mr. J. W. D. Brown, of Lewisham, proposed superposed lenses for signal and lighthouse lanterns, with a separate light for each tier of lenses. In 1872, Mr. John Wigham, of Dublin, pro-

I Friday evening discourse delivered at the - Royal Institution by Sir James N. Douglass, F.R.S., on March I5. We are indebted to the Editor of the Engineer for the use of the woodcuts illustrating this discourse. posed superposed lenses for lighthouses, in conjunction with his large gas flames, and the first application of these was made in I 877 at the Galley Head Lighthouse, County Cork. In 1876 Messrs. Lepaute and Sons, the eminent lighthouse optical engineers of Paris, made successful experiments with superposed lenses and mineral oil flames, and one of their apparatus was exhibited at the Paris International Exhibition of 1878 . The results of these experiments were given by M. Henry Lepaute, in a paper contributed to the Congress at Havre in 1877 , of the French Association for the Advancement of Science. The Eddystone represents the first practical application of superposed lenses of the first order, with oil as the illuminant.

The apparatus at the Eddystone is provided with two sixwick burners of the Trinity House improved type, and has a minimum intensity for clear weather of about 38,000 candle units, and a maximum intensity of about $\mathrm{r} 60,000$ candle units for atmosphere impaired for the transmission of light. The chandelier light in Smeaton's lantern was unaided by optical apparatus. I have found by experiment that the aggregate intensity of the beam from the twenty-four candles was 67 candle units nearly. The maximum intensity of the flashes now sent to the mariner is about 2380 times that of the candle beam, while the annual cost for the mineral oil illuminant is about 82 per cent. less.

The sound signal for foggy weather consists of two bells of $40 \mathrm{cwt}$. each, mounted on the lantern gallery, and rung by machinery. If any wind occurs with the fog, the windward bell is sounded. The distinctive character of the signal is two sounds of the bell in quick succession every half-minute, thus corresponding with the character of the light signal.

The tendency of the curvilinear outline near the base of Sineaton's and of other similar sea towers that have followed it, to elevate the centre of force of heavy waves on the structure, induced me to adopt a cylindrical base for the new lighthouse, which is found to retard the rise of waves on the structure, while it affords a convenient platform for the lightkeepers, and adds very considerably to their opportunities for landing and relief. The Town Council and inhabitants of Plymouth having expressed a desire that Smeaton's lighthouse should be re-erected on Plymouth Hoe, in lieu of the Trinity House sea mark thereat, the Trinity House, who, as custodians of public money, had no funds available for such a purpose, undertook to deliver to the authorities at Plymouth, at actual cost for labour, the lantern, and the four rooms of the tower. These have been re-erected by public subscription on a frustrum of granite, corresponding nearly with the lower portion of Smeaton's tower, and it is to be hoped that it will be preserved by the town of Plymouth as a monument to the genius of Smeaton, and in commemoration of one of the most successful and beneficent works in civil engineering.

It is extremely difficult to estimate, with a fair degree of accuracy, the maximum force of the waves with which some of the most exposed of these sea structures may occasionally have to contend. The late eminent lighthouse engineer, Mr. Thomas Stevenson, F.R.S.E., carried out a long series of experiments with a self-registering instrument he devised for determining the force of sea-waves on exposed structures. He found at the Skerryvore Rock Lighthouse the Atlantic waves there gave an average force for five of the summer months in $1843-44$ of 6II pounds per square foot. The average result for the six winter months of the same year was 2086 pounds per square foot, or three times as great as in the summer months. The greatest force registered was on March 29, I845, during a westerly gale, when a pressure of 6083 pounds, or $2_{4}^{3}$ tons nearly, per square foot was recorded. After smeaton had carefully considered the great defect of the building of Rudyerd at the Eddystone, viz. want of weight, he replied that, "if the lighthou e was to be so contrived as not to give way to the sea, it must be made so strong as that the sea must be compelled to give way to the building." Smeaton also had regard to durability as an important element in the structure, for he adds: "In contemplating the use and benefit of such a structure as this, my ideas of what its duration and continued existence ought to be were not confined within the boundary of one age or two, but extended themselves to look towards a possible perpetuity.' Thus Smeaton soon arrived at the firm conviction that his lighthouse must be built of granite, and of this material nearly all lighthouses on exposed tidal rocks have since been constructed, while those on submerged sandbanks are open structures of iron, erected on screw piles or iron cylinders. The screw pile was the invention of the late Mr. Alexander Mitchell, of Belfast.

We have here a motel of the first lighthouse, erected in $183^{8}$, 
on these screw piles, at the Maplin Sand, on the north side of the estuary of the Thames, under the direction of the late James Walker, F.R.S., then Engineer-in-Chief to the Trinity House. A lighthouse on the principle of minimum surface exposed to the force of the waves, of which we have here a model, was erected on the chief rock of the dangerous group of the Smalls, situated about $18 \frac{1}{2}$ miles off Milford Haven, by Mr. John Phillips, a merchant and shipowner of Liverpool. The work was designed, and erected under great difficulties, by Mr. Henry Whiteside, a native of Liverpool, and a man of great mechanical skill and undaunted courage. Added to his mechanical ability, Whiteside possessed a great love and knowledge of music, and had, previous to the erection of his lighthouse, excelled in the construction of violins, spinnettes, and upright harpsicords. The lighthouse, commenced in $\mathbf{1 7 7 2}$, was intended to be erected on eight cast-iron pillars, sunk deep into the rock; this material was, however, soon abandoned for English oak, as being more elastic and trustworthy. The work was completed and lighted in 1776 with eight lamps and glass faceted reflectors, similar to the one before us. In 1817 sixteen improved lamps and silvered paraboloidal reflectors were substituted for these; and the lighthouse, although sorely tried by winter storms, was (with the aid of yearly repairs and strengthening) enabled to send forth its beneficent beam until the year 1856 , when the Trinity House commenced the erection of a lighthouse of granite, as shown by this model. The vibrations of the old wooden structure must have been very considerable with heavy storms, for the lightkeepers occasionally found it sufficient to cause a bucket of water, placed in the living-room, to spill just half its contents. It was in this lighthouse that the painful circumstance occurred in the year 1802 of the death of one of the lightkeepers. In those days only two men inhabited the lighthouse at a time; one of them was taken ill, and the means employed by his companion for obtaining relief proved ineffectual ; he hoisted a signal of distress, but owing to stormy weather no landing could be effected, and after many days of extreme suffering, the poor fellow, named Thomas Griffiths, breathed his last, when the survivor, Thomas Howell, fully realized the awful responsibilities of his position; decomposition would quickly follow, and the atmosphere of the small apartment would be vitiated. The body could not be committed to the sea, as suspicion of murder would probably follow. Howell was a cooper by trade, and he was thus enabled to make a coffin for his dead companion out of boards obtained from a partition in the apartment. After very great exertion the body was carried to the outer gallery, and there securely lashed to the railing. For three long weeks it occnpied this position before the weather moderated, yet night after night Howell faithfully kept his lights brightly burning. When a landing was at lait effected, his attenuated form demonstrated the sufferings, both mental and physical, he had undergone ; indeed, several of his friends failed to recognize him on his return to hi home. Since this sad occurrence the Trinity House have always maintained three lightkeepers at their isolated rock stations. The present lighthouse was designed by the late Engineer-in. Chief of the Trinity House, Mr. James Walker, F.R.S., and I had the honour of executing the work as resident engineer. The foundation-stone was laid on June 26,1857 , and the light was exhibited on August 7, I86r. The work was completed by the Trinity House, at a cost of $£ 50$, 125, being about 24 per cent. under the lowest amount at which it had been ascertained that it could have been executed by contract.

Probably the most exposed rock lighthouse is that on the Bishop (the westernmost of the rocks of Scilly), shown in Fig. I. Its position is doubtless one of the most important to mariners, warning them, as it does, of the terrible dangers where, on October 22, I707, Sir Cloudesley Shovel, with the Association, Eagle, and Romney, were lost, with about 2000 men. The Bishop is also the guiding light for the entrances to the English and Bristol Channels. The rock, composed of a very hard, pink-coloured granite, is about 153 feet long by 52 feet wide at the level of low water of spring tides. It stands in over 20 fathoms water, is steep to, all round, and is exposed to the full fury of the Atlantic. It was at first feared that the width of the rock was not sufficient for the base of a stone tower of adequate dimensions to withstand the heavy wave-shocks it would have to resist, and an open structure of wrought and cast iron [shown on the diagram] was determined on. The work was jointly designed by the late Engineer-in-Chief to the Trinity Hicuse and my father, the superintending engineer, who after- wards erected the structure, at which I had the honour of acting. as assistant engineer.

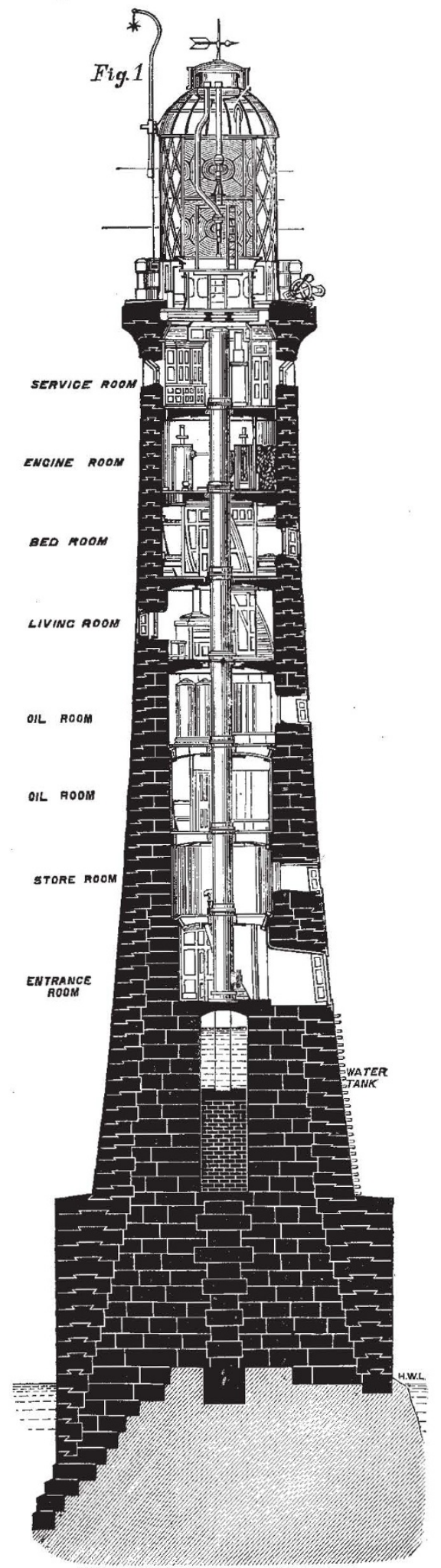

The work was commenced in 1847 , and at the end of the working season of 1850 the lighthouse was so far completed as 
to be in readiness for receiving the lantern and the illuminating apparatus, and it was left with confidence to resist the storms of the approaching winter. But during a very violent storm, between II p.m. of the 5 th and 3 a.m. on the 6 th of the following February, the lighthouse was completely destroyed, and swept. from the rock. On further consideration of the matter, the Trinity House determined, on the recommendation of their engineers, to proceed with a stone structure, and my father was appointed to build the lighthouse, I acting as before as assistant engineer. The work was proceeded with in the spring of $185 \mathrm{I}$. In order to obtain the greatest possible diameter of base for the tower that the rock would admit of, it was found necessary to lay a portion of the foundation on the most exposed side of the rock, at the level of $\mathrm{I}$ foot below low water of spring tides; and, although every possible human effort was made by the leader and his devoted band of workers, the foundations were not completed until the end of the season of 1852 . Soon after this, my brother, Mr. William Douglass, now Engineer-in-Chief to the Commissioners of Irish Lights, succeeded me as assistant engineer at the work. The lighthouse was completed in 1858 , and its dioptric fixed oil light of the first order was first exhibited on September $\mathbf{r}$ of that year. Soon afterwards, its exposure to heavy seas during storms was fully realized. On one occasion the fog bell was torn from its bracket at the lantern gallery at Ioo feet above high water, and the flag-staff, with a ladder, which were lashed outside the lantern, were washed away. The tremor of the tower on these occasions was such as to throw articles off shelves, and several of the large glass prisms of the dioptric apparatus were fractured. After some time it was found that several of the external blocks of granite situated a few feet above high water were fractured by the excessive strains on the building. In 1874 the tower was strengthened from top to bottom by heavy iron ties, bolted to the internal surface of the walls; but, after a violent storm in the winter of $188 \mathrm{I}$, there was evidence of further excessive straining at the face of the lower external blocks of masonry, when the Trinity House, on the advice of their engineer, determined on the reerection of the lighthouse. This was accomplished (as shown in Fig. I) by incasing the existing tower with carefully dovetailed granite masonry, each alternate block of the new granite being dovetailed to the old. The work was one of considerable difficulty, owing to the necessity for maintaining the light throughout the progress ; and the risk to the workmen was great, especially at the upper part of the old tower, owing to the narrow ledge on which the work had to be executed. I am, however, thankful to state that the new lighthouse has been successfully completed by my son, Mr. W. T. Douglass, who was also my assistant engineer at the Eddystone; and with the same complete immunity from loss of life or limb to any person employed, as with the two previous structures on this rock. The optical apparatus con. sists of two superposed tiers of lenses of the type adopted at the Eddystone, but of larger dimensions, as suggested by the late Mr. Thomas Stevenson, for obtaining greater efficiency with the largerflame luminaries recently adopted. The apparatus is provided with two Trinity House improved mineral oil burners, and has a minimum intensity for clear weather of about 80,000 candle units, and a maximum intensity for thick weather of about 513,000 candle units. The character of the light is double-flashing, showing two flashes, each of four seconds' duration, in quick succession, at periods of one minute. The flashes of this light, and those of a light lately completed at about 8 nautical miles from it, on Round Island, are the most intense yet attained with oil flames for beacon lights; and it may be stated that, with no other illuminant at present known to science could these results be carried out within the space available at the Bishop Rock, and under the circumstances attending that work. The fog signal recently adopted at this station, in lieu of the bell, is by the electrical explosion of 4 -ounce charges of gun-cotton, at int ervals of 5 minutes. The apparatus provided for this form of fog signal is shown in Fig. I. It consists of a wrought-iron crane (attached to the lantern) which is raised and lowered by a worm-wheel and pinion. When the crane is lowered, its end reaches near the gallery, where the lightkeeper susfends the charge of gun- cotton, with its detonator attached, to the electric cable, which is carried along the crane and through the roof of the lantern to a dynamo-electric firing machine. After suspending the charge, the jib of the crane is raised to its upper position, when the charge is fired nearly vertically over the glazing of the lantern, and thus without causing damage to it. The large and heavy optical apparatus is rotated automatically by compressed air, which is stored in two vertical steel reservoirs, fixed at the centre of the tower. The air is compressed by a small Davey safety motor. A winch, worked by the compressed air, is fixed on the lantern gallery for landing the lightkeepers, stores, \&c. Fig. $\mathbf{2}$ is a sketch, from actual obser-

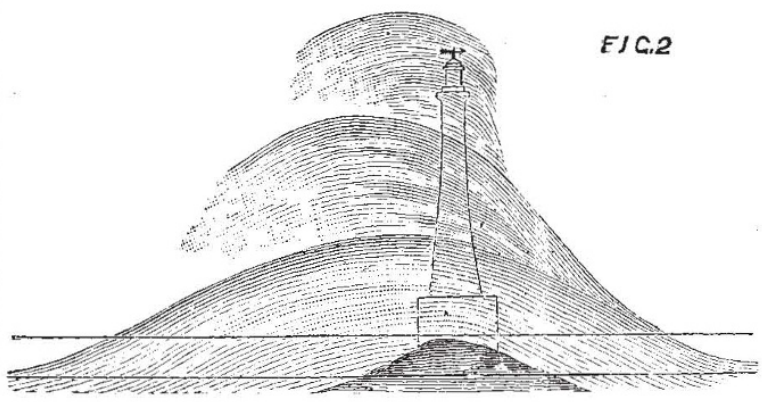

vation, of the height and form of waves on the tower during a storm.

The numerous outlying shoals surrounding the shores of this country, particularly off the east coast, were an early cause of anxiety to those responsible for the guidance of mariners. And in addition to buoys as sea-marks by day, floating lights, as guides by night, were found to be a necessity. The first lightvessel was moored at the Nore Sand in 1732, and another near the Dudgeon Shoal in 1736 . We have here a model of the latter vessel, from which we may judge of the pluck and hardihood of the crews who manned them, especially when we remember that there were no chain cables in those days, the

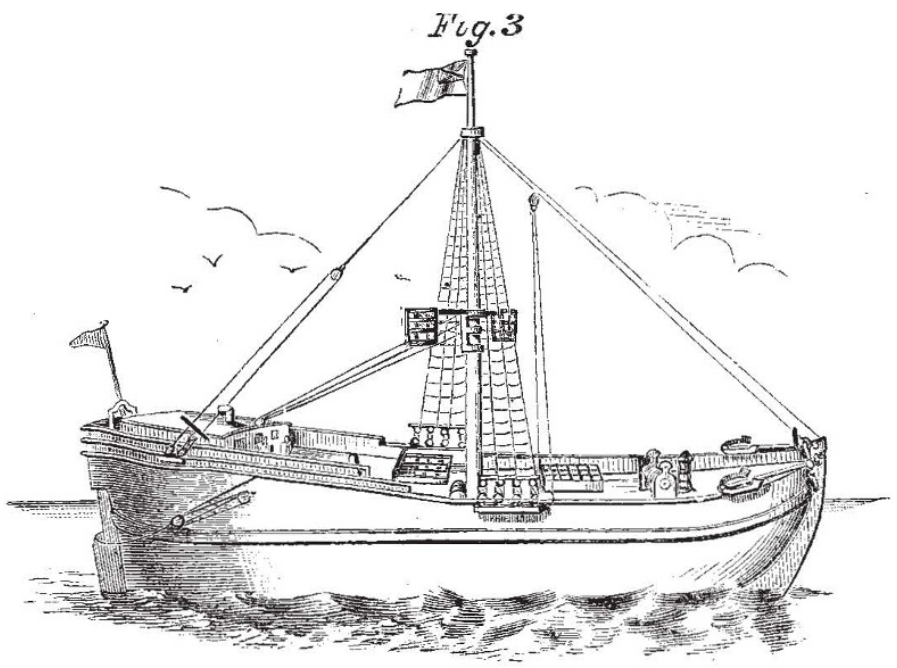

vessel having to be moored with a cable of hemp, which, owing. to the constant chafing, occasionally parted during winter storms, when, to save their lives, the crew had to put out another anchor if possible, or set such storm canvas as they could to keep her off a lee-shore, and endeavour to reach a place of safety. The illuminating apparatus of these vessels consisted of a small lantern and flat-wick oil lamps, fixed at a yardarm, and here appears to have occurred the first application of a distinctive character to beacon lights, for the Dudgeon was fitted with two lights, one being placed at each arm of the yard (Fig. 3). The next light-vessel was placed at the Newarp Shoal in 1790 , and in 1795 one was placed at the north end of the Goodwin Sands. 
The two latter vessels were provided with three fixed lights, and the lanterns were larger, and surrounded each mast-head, as shown by the model before us. An improvement was also effected in these lights by providing each lamp with a silvered reflector.

In 1807 the late Mr. Robert Stevenson, the engineer of the Bell Rock Lighthouse, to whom and his successors are due much valuable engineering and optical work connected with coast-lighting, designed a larger lantern to surround the mast, and capable of bing lowered to the deck for properly trimming the lamps (Fig. 4). Soon after the adoption of the system of catoptric illumination in lighthouses, it was extendecl to floating lights; each lamp and reflector was hung in gimbals, to insure horizontal direction of the beam; of light during the pitching and rolling of the vessel. We have here one of these apparatus. The intensity of the beam sent from it was 500 candle units, nearly.
On January I, 1837, the Trinity House installed the first revolving floating light, at the Swin Middle, and later in the same year another, on board the Gull light-vessel. The lamps and reflectors were carried on a roller frame surrounding the mast, and rotated through light shaftings by clockwork placed between decks. There were nine lamps and reflectors arranged in three groups, of three each, and thus the collective intensity of each flash was equal to that of three fixed lights, or I500 candle units, nearly. In 1872 the Trinity HIouse further increased the dimensiors of the lanterns and reflectors of their floating lights--the lanterns from 6 to 8 feet in diameter, with cylindrical instead of polygonal glazing, and the reflectors from 12 inches to $2 \mathrm{I}$ inches diameter at the aperture. These improvements, together with the adoption of improved burners, have effected a considerable increase in the intensity of these lights; and during the last two years a further improvement has been obtained by the adoption of concentric wick burners with

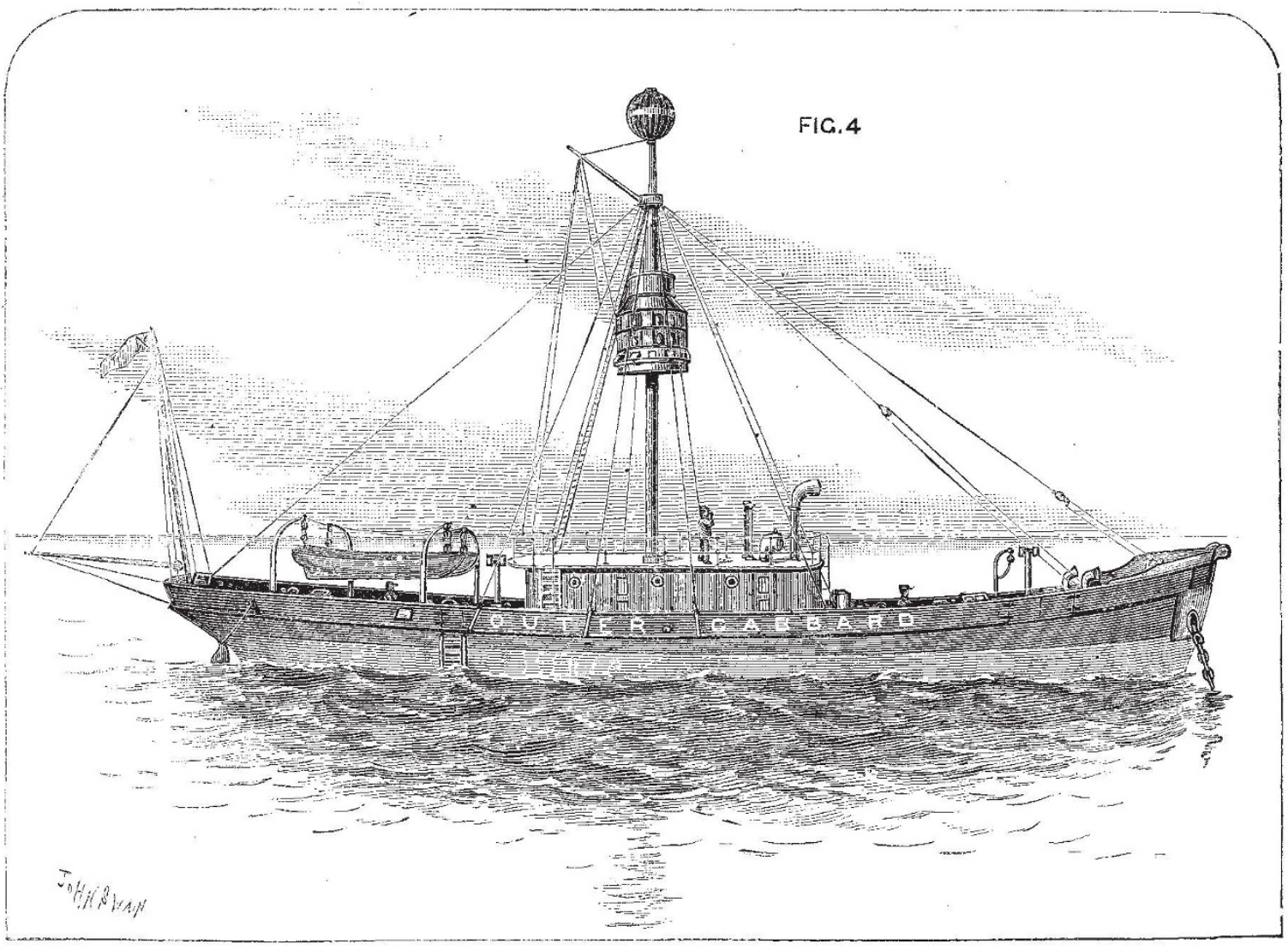

more condensed flimes, and of higher illuminating power, by which the intensity of the beam from each reflector has been raised to 5000 candle units, being just ten times the intensity of the smaller apparatus; while, by the adoption of mineral oil in lieu of colza, the annual cost for the illuminant has been reduced 50 per cent.

Dioptric apparatus was proposed for light-vessels by M. Letourneau in $185 \mathrm{I}$, several small fixed-light apparatus being intended to be employed in each lantern, and arranged nearly in the same way as the reflectors. This arrangement has been adopted in some instances by Messrs. D. and T. Stevenson, Engineers to the Commissioners of Northern Iighthouses, and by the engineers of the French I.ighthouse Service; but, for efficiency and adaptability to meet the rough duty to which foating lights are occasionally subjected in stormy weather and collisions, this system has been found to be inferior for this service to the catoptric.

An intere ting experiment was recently made by the Mersey Docks and Harbour Board with the electric arc light, on board one of their light-vessels, at the entrance of the Mersey; but unfortunately it did not prove successful. The present difficulties experienced afloat with this powerful illuminant will doubtless be overcome, and it will be found to be, as in lighthouses, by far the most efficient illuminant for some special stations, where a higher intensity than can be obtained with flame luminaries is demanded. Experiments have been in progress during the past two years at the Sunk light-vessel, off the coast of Essex, for maintaining electrical telegraphic communication with the shore for reporting wrecks and casualties in the Iocality. This vessel is connected with the post office at Walton-on-Naze, through nine miles of cable. The instruments adopted are the Wheatstone ABC Morse, and the Gower Bell telephone, the telephone for the first time for this purpose on board a vessel at sea, and its efficiency has been found to be so perfect that it is preferred by the operators to the telegraphic instruments. Many difficulties have been experienced in maintaining trustworthy communication during stormy weather, owing to consequent wear and tear of the connections with the vessel, but the system, which was designed 
and carried out by the Telegraph Construction and Maintenance Company, is now working satisfactorily. Unfortunately, however, it is found to be too costly for adoption except in very special cases.

(To be continued.)

\section{A BILL TO PROVIDE TECHNICAL EDU-} CATION IN ENGLAND AND WALES.

THE following Bill, introduced into the House of Commons by Sir Henry Roscoe on behalf of the National Association for the Promotion of Technical Education, was read a second time without opposition on Wednesday, May 8 :-

Whereas it is expedient that due provision should be made for technical education in public elementary schools and elsewhere:

$\mathrm{Be}$ it therefore enacted by the Queen's most Excellent Majesty, by and with the advice and consent of the Lords Spiritual and Temporal, and Commons, in this present Parliament assembled, and by the authority of the same, as follows :

I. This Act may be cited as the Technical Education Act, I88c.

2. (I) After the passing of this Act any school board may make provision for giving technical education in any school under their management, and either by day or evening classes, or both, as may seem fit, having regard to the daily occupations of the persons to be benefited thereby.

(2) If no such provision is made, or if it is insufficient, and if the local authority by special resolution determine that provision or further provision ought to be made, they may them. selves make such provision.

3. Where technical education is given in any school, not being a public elementary school (including for the purposes of this section any college), which is not under the management of a school board or local authority, and is either within their district or accessible to the inhabitants thereof, the school board or local authority may contribute or they may join together with other school boards or local authorities in contributing from their respective funds towards -

(a) the maintenance or improvement of that school or of its provisions for technical education ; or

(b) the payment of the fees at that school of deserving students who before proceeding to such school have been resident in the district of the contributing board or authority ;

(c) the establishment of scholarships for deserving students.

The mode in which and the terms upon which contributory school boards and local authorities shall be represented upon the governing bodies of schools receiving such contributions, so far as technical instruction is concerned, shall be such as may be agreed upon between the school boards, local authorities, and governing bodies respectively in each case.

Fvery such contribution shall be deemed to be expenses of such school board or local authority incurred for the purposes of this Act.

4. (I) Where any school in which technical education is siven in pursuane of this Act is also a publis elementary school, a parlia. mentary grant may be made to such school by the Education Department and by the Science and Art Department, or by either of such Departinents.

(2) The conditions requived to be fulfilled by such school in oraer to obtain an annual parliamentary grant shall be those contained in minutes issued by the Committee of Counit on Eaucation.

(3) Any minute made in pursuance of this section shall not come into force until it has lain on the table of both Houses of Parliament for one month.

5. (I) Where any school in which technical education is given in pursuance of this Act is no: a public e'ementary school, a parliamentary grant may be made to such school by the Science and Art Department, subject to such conditions as that Department may prescribe.

(2) Any minute made by the Science and Art Department in pursuance of this section shall not come into force until it has lain on the table of both Houses of Parliament for one month.

6. (I) All the provisions of the Elementary Education Acts relating to the powers of school boards with respect to sufficient accommodation, fees, the combination of school boards, and the acquisition of land, shall apply to school boards in whose schools technical education is given, or to be given, under this Act; and a school shall not cease to be a public elementary school within the meaning of the Elementary Education Acts by reason of technical education being given therein.

(2) A school which is under the management of a school board, and in which technical education is given under this Act, shall be conducted in accordance with the same regulations as an elementary public school under the Elementary Education Acts : Provided, however, that every such school shall be open to the inspection of any inspector appointed by the Department of Science and Art, as well as of Her Majesty's inspectors as defined in the Elementary Education Acts.

7 . The expenses incurred by any school board in carrying this Act into effect, including any contributions made by the schoo board in aid of technical education in schools not under their management, shall be deemed to be expenses of the said schoo. board within the meaning of the Elementary Education Acts, and payable accordingly.

A schuol board shall have the same powers of borrcwing for the like purposes, but subject to the same consent and other conditions, as they have under the Elementary Education Acts.

8. The expenses incurred by a local authority in giving effect to this Act, including any stuch contributions as are above mentioned, shall be payable out of the local rate. The local authority shall have the like powers of borrowing for the purposes of this Act, but subject to the same conditions, as for other purposes.

9. The provisions of this Act with respect to a local authority shall not apply to the Metropolis.

10. It shall be competent for any school board or local authority, should they think fit, to institute an entrance examination in reading, writing, and arithmetic for persons desirous of attending technical schools or classes under their management, or to which they contribute.

II. For the purposes of this Act the expression "technical education " means instruction in-

(i.) Any of the branches of Science and Art with respect to which grants are for the time being made by the Department of Science and Art.

(ii.) The working of wocd, clay, metal, or other material for the purposes of art or handicraft.

(iii.) Commercial arithmetic : commercial geography ; modern languages; book-keeping, and shorthand.

(iv.) Any other subject applicable to the purposes of agriculture, trade, or commercial life and practice, which may be sanctioned by a minute of the Department of Science and Art made on the representation of a school board or local authority that such a form of instruction is suited to the needs of its district.

12. The provision to be made for technical education under this Act may include the providing of school laboratories, apparatus for teaching and experiment, museums and their contents, libraries, books, workrooms, schools or schoolrooms, or the improvement of existing provisions of any of these kinds, and the maintaining of the same in such manner as may be necessary to give effect to this Act.

13. (I) Save as otherwise provided by this Act the expressions "school board," "public elementary school," "managers," "parliamentary grant," and "Education Depaitment," respectively, have the same meaning in this Act as in the Elementary Education Acts.

(2) The expression "local authority" means in any borough the council of that borough, and elsewhere the district council if district councils are established under any Act of the present session of Parliament, but if not then the urban sanitary authority or where there is no urban sanitary authority the county council.

The expression "Jocal rate" means in a borough the school fund or borough fund or borough rate, and elsewhere the genera! district rate or other rate corresponding thereto.

I4. This Act thall not apply to Scotland or Ireland.

\section{SCIENTIFIC SERIALS.}

Eulletins de la Sociaté d'Anthrótogie, tome onzième, série iii., fasc. 4 (Paris, I 888). - Conclusion of M. Variot's paper on the $r \in$ moval of marks of tattooing; and on an instrument for tattooing, by the same writer. - On the sacrum of a chimpanzee, by M. Chudzinski. In this case the sacrum was composed of seven vertebra, the normal number in the Anthropoids being only five, or at most six.-A process for mounting histological specimens 